\title{
Features of Morphometric Parameters of the Placenta in Post-Term and Normal Pregnancy in Mongolian Women, Taking into Account the Placental-Fetal Ratio
}

\author{
Erdenebat Saruulsaikhan, Dorjkhvv Amgalanbaatar, Jamsranjav Enkhtsetseg, Sundui Enebish \\ Department of Obstetrics and Gynecology, Mongolian National University of Medical Sciences, Ulaanbaatar, Mongolia \\ Email: fbm16f005@gt.mnums.edu.mn
}

How to cite this paper: Saruulsaikhan, E., Amgalanbaatar, D., Enkhtsetseg, J. and Enebish, S. (2021) Features of Morphometric Parameters of the Placenta in Post-Term and Normal Pregnancy in Mongolian Women, Taking into Account the Placental-Fetal Ratio. Open Access Library Journal, 8: e8214. https://doi.org/10.4236/oalib.1108214

Received: November 22, 2021

Accepted: December 5, 2021

Published: December 8, 2021

Copyright $\odot 2021$ by author(s) and Open Access Library Inc.

This work is licensed under the Creative Commons Attribution International License (CC BY 4.0).

http://creativecommons.org/licenses/by/4.0/

Open Access

\begin{abstract}
Objective: To study the morphometric features of the placenta in Mongolian women with normal and post-term pregnancy in a comparative aspect. Materials and Method: The material for the study was the placenta taken after childbirth from 366 mothers with post-term pregnancies and 695 mothers with normal pregnancies who gave birth in 2017-2018. Morphometric measurement methods were used. For statistical processing of the results obtained, the statistical data analysis package SPSS 23 (IBM) was used. Results: The length of the placenta in women with normal pregnancy was $18.518 \pm 1.468$ $\mathrm{cm}$, and with post-term pregnancy $19.485 \pm 1.824 \mathrm{~cm}(\mathrm{t}=8.75),(\mathrm{p}<0.001)$. In women with normal pregnancy, the width of the placenta was $18.150 \pm$ $1.565 \mathrm{~cm}$, and in women with post-term pregnancy, $18.982 \pm 1.897 \mathrm{~cm}(\mathrm{t}=$ $7.20)$, ( $\mathrm{p}<0.001)$. The thickness of the placenta in women with normal pregnancy was $1.997 \pm 0.388 \mathrm{~cm}$, in women with post-term pregnancy $2.005 \pm$ $0.432 \mathrm{~cm}(\mathrm{t}=0.30)$. The average weight of the placenta was $628.45 \pm 86.298 \mathrm{~g}$ in women with normal pregnancy, and $721.21 \pm 118.166 \mathrm{~g}$ in women with post-term pregnancy $(\mathrm{t}=13.27),(\mathrm{p}<0.001)$. The average weight of a newborn was $3444.73 \pm 267.766 \mathrm{~g}$ in the group with normal pregnancy, and $4094.39 \pm 302.624 \mathrm{~g}$ in the group with post-term pregnancy, $(\mathrm{p}=0.000)$. The placental-fetal ratio was $0.183 \pm 0.00099$ in the group with normal pregnancy, and $0.176 \pm 0.00157$ in the group with post-term pregnancy, $(\mathrm{t}=3.77),(\mathrm{p}<$ 0.001). Conclusion: The average values of the morphometric parameters of the placenta during post-term and normal pregnancy have a difference, being within the normal range. As the gestational age increases, the length, width, thickness, and weight of the placenta increase in different ways.
\end{abstract}




\section{Subject Areas}

Gynecology \& Obstetrics

\section{Keywords}

Post-Term Pregnancy, Placenta, Morphometry

\section{Introduction}

The objective of this study, to study the morphometric features of the placenta in Mongolian women with normal and post-term pregnancy in a comparative aspect.

The placenta is a provisional organ that connects the developing fetus through the umbilical cord to the wall of the uterus. The placenta consists of two parts: embryonic or fetal and maternal. The placenta plays a very important role during pregnancy and its pathologies increase the risk of morbidity or mortality for a woman, a fetus [1] [2]. The size of the placenta in normal and post-term pregnancies differs. Post-term pregnancy is a pregnancy that lasts more than 42 weeks [2] [3]. According to our researchers, in Mongolia, post-term pregnancy accounts for $6 \%$ of all births, and in the western region of Mongolia-2 percent of all births [4] [5]. The pathogenesis of prolonged pregnancy is largely determined by changes in the placenta [6]. After 37 - 38 weeks of pregnancy, the placenta reaches its maximum size and its functions begin to decline. With a post-term pregnancy, the placenta tends to age and secrete calcifications that prevent the normal flow of nutrition and oxygen to the fetus [7]. After 43 weeks of gestation, the placenta becomes heavier than normal, which is associated with compensatory hyperplasia of the villi [8]. Placental insufficiency occurs when the placenta cannot deliver adequate oxygen and nutrients to the infant [9].

\section{Method}

The material for the study was the placenta taken after childbirth from women aged 17 to 44, who was born at the National Center for Maternal and Child Health and in maternity hospitals "Urguu", "Khuree" and "Amgalan" of the capital from 366 mothers with post-term pregnancies and 695 mothers with normal pregnancies in 2017-2018. The timing of pregnancy was determined not in days, but weeks plus days. Women with placental pathology were excluded. We carried out a prospective analysis.

\subsection{Morphometric Measurements}

Initially, the placenta was carefully rinsed with water to remove excess clots and amniotic residues. Then the length (maximum diameter) and width (minimum diameter) of the placenta were determined with the help of a measuring tape. The thickness of the placenta was measured only in the center with the help of 
the iron line. The results were recorded in centimeters [10]. Placental weights were measured electronically.

\subsection{Statistical Analysis}

The description of the indicators of statistical analysis used the average arithmetic (M) and standard deviation (SD), standard error (SE), minimum (min), maximum (max), and scale (Range). Calculated placental-fertility coefficient (PPC) - the ratio of the mass of the placenta to the mass of the fetus. The statistical significance of the difference between the indicators was assessed by the $\mathrm{t}$-criterion of the student [11]. The statistical package of data analysis SPSS 23 (IBM) was used for statistical processing of the results obtained [12]. For all types of analysis, statistically, significant values were calculated at the level of $\mathrm{p}<$ 0.05 .

\section{Results}

In the current study, we compared macro morphometric indicators of the placenta during pregnancy and normal pregnancy.

Length (and large diameter) of the placenta.

The length of the placenta in a woman with normal pregnancy ranges from 14.0 to $23.0 \mathrm{~cm}$, with an average length of $18,518 \pm 1468 \mathrm{~cm}$. And the length of the placenta in a woman with a miscarriage varies from 14.0 to $25.0 \mathrm{~cm}$. The median length was $19,485 \pm 1824 \mathrm{~cm}$ (Table 1 and Table 2).

The difference between the length of the placenta in a woman with normal pregnancy and in a woman with a miscarriage was statistically significant $(\mathrm{t}=$ 8.75), $(\mathrm{p}<0.001)$.

\subsection{Width (on and Smaller Diameter) of the Placenta}

The width of the placenta in a woman with normal pregnancy was in the range of $12.0-23.0 \mathrm{~cm}$, with an average width of $18,150 \pm 1565 \mathrm{~cm}$. And the width of the placenta in a woman with a miscarriage was 13.0 to $25.0 \mathrm{~cm}$. At this time the average width of the placenta was $18,982 \pm 1897 \mathrm{~cm}$ (Table 1 and Table 2).

Table 1. Morphometric indicators of placenta at normal pregnancy.

\begin{tabular}{|c|c|c|c|c|c|c|c|}
\hline \multirow{2}{*}{ Indicators } & \multicolumn{7}{|c|}{ Morphometric indicators of placenta at normal pregnancy } \\
\hline & $\mathbf{N}$ & M & SD & SE & Min & $\operatorname{Max}$ & Range \\
\hline $\begin{array}{l}\text { The length of } \\
\text { the placenta }\end{array}$ & 695 & 18.518 & 1.468 & 0.056 & 14.00 & 23.00 & 9.00 \\
\hline $\begin{array}{l}\text { Width of } \\
\text { the placenta }\end{array}$ & 695 & 18.150 & 1.565 & 0.059 & 12.00 & 23.00 & 11.00 \\
\hline $\begin{array}{l}\text { The thickness } \\
\text { of the placenta }\end{array}$ & 695 & 1.997 & 0.388 & 0.015 & 0.80 & 4.00 & 3.20 \\
\hline Mass of placenta & 695 & 628.45 & 86.298 & 3.273 & 310.0 & 880.0 & 570.0 \\
\hline
\end{tabular}


Table 2. Morphometric indicators of placenta post-term pregnancy.

\begin{tabular}{|c|c|c|c|c|c|c|c|}
\hline \multirow{2}{*}{ Indicators } & \multicolumn{7}{|c|}{ Morphometric indicators of placenta post-term pregnancy } \\
\hline & $\mathbf{N}$ & M & SD & SE & Min & $\operatorname{Max}$ & Range \\
\hline $\begin{array}{l}\text { The length of } \\
\text { the placenta }\end{array}$ & 366 & 19.485 & 1.824 & 0.095 & 14.00 & 25.00 & 11.00 \\
\hline $\begin{array}{l}\text { Width of } \\
\text { the placenta }\end{array}$ & 366 & 18.982 & 1.897 & 0.099 & 13.00 & 25.00 & 12.00 \\
\hline $\begin{array}{l}\text { The thickness } \\
\text { of the placenta }\end{array}$ & 366 & 2.005 & 0.432 & 0.023 & 1.00 & 4.00 & 3.00 \\
\hline Mass of placenta & 366 & 721.21 & 118.166 & 6.177 & 330.0 & 1000.0 & 670.0 \\
\hline
\end{tabular}

When comparing the width of the placenta between groups, it was found that the difference between the width of the placenta in a woman with normal and with a miscarriage was statistically significant $(t=7.20),(p<0.001)$.

\subsection{Mass of Placenta}

The mass of the placenta in women with normal pregnancies was in the range of $310.0-880.0 \mathrm{~g}$ with an average mass of $628.45 \pm 86.298 \mathrm{~g}$. And the mass of the placenta in a woman with a miscarriage varies from 330.0 to $1000.0 \mathrm{~g}$. The average weight was $721.21 \pm 118,166$. The mean weight of the placenta of a post-term pregnancy mother was $721.21 \pm 118,166 \mathrm{~g}$ (Table 2).

When comparing the weight of the placenta between groups, the difference in the weight of the placenta in a woman with normal pregnancy and in a woman with a miscarriage was statistically significant $(\mathrm{t}=13.27),(\mathrm{p}<0.001)$.

\subsection{Weight in Newborns}

In our study, the mean weight of the newborn was in the group with normal pregnancy $3444.73 \pm 267.766 \mathrm{~g}$, and fluctuated from 2700 to $4200 \mathrm{~g}$, and with abnormal pregnancy $4094.39 \pm 302.624 \mathrm{~g}$, and fluctuated from 3050 to 54 ( $\mathrm{p}=$ 0.000) (Table 3).

\subsection{Placental-Fetal Coefficient}

We calculated the placental-fertile ratio (PPC) - the ratio of the mass of the placenta to the mass of the fetus. According to our calculations, the placental-fertility ratio was $0.183 \pm 0.00099(\mathrm{PPK}=0.18)$ in the group with normal pregnancy, and $0.176 \pm 0.00157(\mathrm{PPK}=0.17)$ in the group with abnormal pregnancy (Table 4).

When comparing the placental-fertility coefficient between groups of normal and transferred pregnancy, we obtained statistically significant differences $(\mathrm{t}=$ 3.77), $(\mathrm{p}<0.001)$.

\section{Discussion}

Many researchers note that the mass and size of the placenta increase during 
Table 3. Weight of newborns at normal and overweight pregnancy.

\begin{tabular}{cccccccc}
\hline & \multicolumn{6}{c}{ Weight of newborns at normal and overweight pregnancy } \\
\cline { 2 - 8 } Indicators & N & M & SD & SE & Min & Max & Range \\
\hline $\begin{array}{c}\text { Group with } \\
\text { normal Pregnancy }\end{array}$ & 695 & 3444.3 & 267.766 & 10.157 & 2700 & 4200 & 1500 \\
$\begin{array}{c}\text { Group with post-term } \\
\text { Pregnancy }\end{array}$ & 366 & 4094.3 & 302.624 & 15.818 & 3050 & 5450 & 2400 \\
\hline
\end{tabular}

Table 4. Placental-fetal coefficient at normal and abnormal pregnancy.

\begin{tabular}{ccccccccc}
\hline & \multicolumn{7}{c}{ Placental-fetal coefficient } & at normal and abnormal pregnancy \\
\cline { 2 - 8 } Indicators & $\mathrm{N}$ & $\mathbf{M}$ & SD & SE & Min & Max & Range \\
\hline $\begin{array}{c}\text { Group with } \\
\text { normal } \\
\text { Pregnancy }\end{array}$ & 695 & 0.183 & 0.00099 & 0.0263 & 0.08 & 0.28 & 0.20 \\
$\begin{array}{c}\text { Group with } \\
\text { post-term } \\
\text { Pregnancy }\end{array}$ & 366 & 0.176 & 0.00157 & 0.03010 & 0.08 & 0.25 & 0.17 \\
\hline
\end{tabular}

abnormal pregnancy compared to normal pregnancy [13]. In our study, the average length of the placenta in a woman with a normal pregnancy was 18,518 \pm $1,468 \mathrm{~cm}$, and the length of the placenta in a woman with a miscarriage was $19,485 \pm 1,824 \mathrm{~cm}$. And the width of the placenta in women with normal pregnancies averaged $18,150 \pm 1,565 \mathrm{~cm}$, the width of the placenta in women with abnormal pregnancies $-18,982 \pm 1,897 \mathrm{~cm}$. (The width of the placenta of the mother who was bornpost-term pregnancies $18,982 \pm 1,897 \mathrm{~cm}$ ) (Table 2). Some researchers have determined the size of the placenta, as the diameter, the average length, and width. Soni and others determined that at normal pregnancy the diameter of the placenta is $15-25 \mathrm{~cm}$, Sherin and others determined that the diameter of the placenta is $15.07 \mathrm{~cm}$. At this time, the average diameter of the placenta during ectopic pregnancy was $19.67 \mathrm{~cm} \mathrm{[14]} \mathrm{[15].}$

The mass of the placenta at normal and abnormal pregnancy is a widely studied indicator [16] [17]. In our study, the mean weight of the placenta at normal pregnancy was $628.45 \pm 3.273 \mathrm{~g}$, and at post-term pregnancy-721.21 $\pm 118,166 \mathrm{~g}$, (the mean weight of the placenta of a post-term pregnancy mother was 721.21 \pm $118,166 \mathrm{~g}$ ) (Table 2). There is a technicalerror, which was relatively heavier than the normal birth rate of other placentas [18]. In 2017, Soni et al. found a study that found that the average weight of the placenta at normal pregnancy is 468.4 $\mathrm{g}$, in the range from 342 to $568 \mathrm{~g}$. And Sherin and others found that it is $513.38 \mathrm{~g}$ [15] [19]. Zaidi and others (2013) stated that it is $513.16 \mathrm{~g}$ [20] [21]. Burkitova A. $M$. and others note that the mass of the placenta when transferred increases to 100 - $400 \mathrm{~g}$ in comparison with the norm, the fetal-placental coefficient is $0.12 \pm$ 0.01 [13]. The results basically correspond to our data. It was also reported that ethnic affiliation and some unknown factors may affect the mass of the placenta 
[15]. Some differences in the average placental indicator in researchers may also be related to differences in the method of preparation and measurement of the placenta.

The mean values and range of morphometric parameters of the placenta in a woman with normal pregnancy and in a woman with a post-term pregnancy are within the limits of the norm. When comparing the placental-fertility coefficient between groups, statistically significant differences were obtained $(t=3.77),(p<$ $0.001)$. In our opinion, the differences obtained in the comparison of placental-fertility coefficient between groups of normal and pos-term pregnancy, mean that the change in the placenta is a sign of pos-term pregnancy. There are some restrictions in the current investigation. We compared only some macromorphometric features of the placenta in women with normal pregnancy and in women with post-term pregnancy. In future studies, it is necessary to study the difference in the histological and molecular levels of the placenta in women with normal and pos-term pregnancies. The risk factor for the anatomical features of the human placenta was not included in the results of this study.

\section{Conclusion}

The average values of the morphometric parameters of the placenta during postterm and normal pregnancy have a difference, being within the normal range. As the gestational age increases, the length, width, thickness, and weight of the placenta increase in different ways.

\section{Conflicts of Interest}

The authors declare no conflicts of interest.

\section{References}

[1] Avirmed, A., Amgalanbaatar, D., et al. (2019) Human Embryology. Soyomboprinting, Ulaanbaatar, 220. (In Mongol.)

[2] Chang, J.-M., Mulgrew, A. and Salafia, C. (2012) Characterizing Placental Surface Shape with a High-Dimensional Shape Descriptor. Applied Mathematics, 3, 954-968. http://www.SciRP.org/journal/am https://doi.org/10.4236/am.2012.39143

[3] Health Development Center (2015) Health Indicators. Ulaanbaatar.

[4] Managing Post-Term Pregnancy. https://www.ausmed.com/cpd/articles/post-term-pregnancy

[5] Erkhembaatar, T. and Lkhagva-Ochir, E. (2013) Obstetric Problems. Soyombo Printing, Ulaanbaatar. (In Mongol.)

[6] Solongo, T. (2016) On the Issue of Perinatal Mortality in the Western Region of Mongolia. Mongolian National University of Medical Sciences, Ulaanbaatar.

[7] Strizhakov, A.N., Ignatko, I.V., Timohina, E.V. and Rybin, M.V. (2006) Perenoshennaya Beremennost. Dinastiya, Moscow, 145 c. (In Russ.)

[8] https://mcgenesis.ru/zdorovie-i-lechenie/perenoshennaya-beremennost

[9] Ghani, N. and Yadav, K. (2018) Comparative Study on Macroscopic Morphology of 
Human Placenta in Preterm, Term \& Post Term Pregnancy. International Multispecialty Journal of Health, 4, 109-114.

[10] Briscoe, D., Nguyen, H., Mencer, M., Gautam, N. and Kalb, D.B. (2005) Management of Pregnancy beyond 40 Weeks' Gestation. American Family Physician, 71, 1935-1941.

[11] Yetter, J.F. (1998) Examination of the Placenta. American Family Physician, 57, 10451054.

[12] Lakin, G.F. (1990) Biometrics. Textbook for the Biological Specialties of Universities. 4th Edition, The Higher School, Moscow, 352 p. (In Russian)

[13] http://www.datuapstrade.lv/rus/spss

[14] Burkitova, A.M., Polyakova, V.O., Bolotskikh, V.M. and Kvetnoy, I.M. (2019) Features of the Structure of the Placenta in Post-Term Pregnancy. Journal of Obstetrics and Women's Diseases, 68, 73-86. https://doi.org/10.17816/JOWD68673-86

[15] Ullberg, U., Sandstedt, B. and Lingman, G. (2001) Hyrtl's Anastomosis, the Only Connection between the Two Umbilical Arteries. A Study in Full-Term Placentas from Aga Infants with Normal Umbilical Artery Blood Flow. Acta Obstetricia et Gynecologica Scandinavica, 80, 1-6. https://doi.org/10.1080/791201785

[16] Sherin, F., Afzal, E. and Seema, N. (2015) Gross Morphological Changes in Premature and Post Mature Human Placentae. Journal of Ayub Medical College Abbottabad, 27, 448-450.

[17] Afodun, A.M., Ajao, M.S. and Enaibe, B.U. (2015) Placental Anthropometric Features: Maternal and Neonate Characteristics in North-Central Nigeria. Advances in Anatomy, 2015, Article ID: 790617. https://doi.org/10.1155/2015/790617

[18] Olaleye, A.A., Nwafor, J.I., Ebere, I.C., Ibo, C.C., ChibuzorUgoji, D.-P., Obi, N.C. Asogwa, S.U. and Adiele, A.N. (2019) The Relationship between the Weight of the Placenta and Birth Weight of Term Neonate Delivered in Alex Ekwueme Federal University Teaching Hospital Abakaliki, Nigeria. Advances in Reproductive Sciences, 7, 82-93. https://doi.org/10.4236/arsci.2019.74010

[19] Cunningham, F., Leveno, K., Bloom, S., Spong, C.Y. and Dashe, J. (2014) Williams Obstetrics. 24th Edition, McGraw-Hill, New York.

[20] Zaidi, M., Arshad, M., Vasenwala, S., Faruqi, N., Khan, A. and Khan, S. (2013) Histomorphometry of Preterm and Term Human Placentas. International Journal of Morphology, 31, 409-413. https://doi.org/10.4067/S0717-95022013000200007

[21] Sachin, S., Kamal, B., Shikky, G. and Sandeep, K.M. (2017) Study of an Arterial Pattern of Normal Human Placenta in Reference to Its Shape, Weight and Hyrtl's Anastomosis. International Journal of Medical Research and Review, 5, 455-461. https://doi.org/10.17511/ijmrr.2017.i05.03 